Research Article

\title{
THE EVALUATING OF WIND ENERGY POTENTIAL OF DIYYARBAKIR USING WEIBULL AND RAYLEIGH DISTRIBUTION
}

\section{Fatih KOÇYİĞIT ${ }^{*}$}

In comparison to fossil fuel that pollutes the lower layer of the atmosphere, wind energy is an alternative clean source of energy. Wind speed is the parameter with primary importance in designing and studying the wind energy conversion systems. In this study, the statistical analysis of the parameters of wind power density and wind speed distribution was investigated using the wind speed data of Diyarbaklr province between the years 2014 and 2018 that were hourly measured by the General Directorate of Meteorology. Wind data are used to derive probability distributions, and their distributional parameters are determined. Two probability density functions are suited to the measured probability distributions on a yearly basis. The Weibull and the Rayleigh models are used to analyze the wind energy potential of the location. This modeling process was evaluated according to R2, RMSE and $\chi 2$ parameters. In conclusion, the values obtained by the Weibull model gave better results than the values obtained by the Rayleigh model in the wind data analysis of Diyarbakır province.

Key words: Wind Energy, Rayleigh Distrubition, Weibull Distrubition

\section{Introduction}

As the world population grows rapidly, the demand for energy increases proportionally. Despite the increasing demand for energy, limited fossil fuel reserves, quality energy and the efficient use of energy produced have become important issues especially in developing countries like Turkey. Turkey has a fairly high level of renewable energy sources to meet a certain part of the total demand for energy [1]. Wind energy has a renewable property and is also known as an environmentally clean energy source among these energy sources [2]. There is no transport problem in wind energy, and also its use does not require a high technology. Wind is formed by the temperature and pressure difference caused by the warming and cooling of the atmosphere. Wind is a stable, reliable, continuous and kinetic energy source. Especially in recent years, investments in converting wind power potential into electric energy have been increasing much faster along with the development of turbine technology. In order to benefit from wind energy which exists as long as the sun and the world exist and is a renewable energy source, it needs to be converted to another form of energy [3]. With the help of meteorological data, distributions of the most suitable regional wind regimes can be determined by using various computer programs [45]. In addition, in many studies, meteorological data were used for statistical analysis in solar energy applications [6-9]. In the studies carried out in the literature, the wind speed frequency distribution is

\footnotetext{
${ }^{1}$ Department of Airframes and Powerplanets, School of Civil Aviation, Dicle University, Turkey (fatih.kocyigit@dicle.edu.tr) http://orcid.org/0000-0001-6383-3163
} 
shown using different distributions such as Gamma, log normal, Rayleigh. On the other hand, the twoparameter Weibull distribution and the one-parameter Rayleigh distribution are the methods that have been used to represent the wind distribution of many regions of the world in recent years. The reasons for using these methods are the factors such as their good compliance with the wind distribution, the flexibility of the distributions, the ease of determination of parameters, small number of parameters, predictability of different heights after determining parameters for a height [10]. Hourly average wind speed data measured at a height of 30 meters at Diyarbakır meteorological station of the Turkish State Meteorological Service between the years 2014 and 2018 were used in this study. Weibull and Rayleigh functions were analyzed statistically to determine the wind energy potential of Diyarbakır province. Statica and Matlab programs were used in the analyses of the study. Weibull and Rayleigh probability density function, cumulative distribution function, average wind speed, standard deviation of wind speed, maximum wind speed and wind power density were determined in statistical analyses. The root mean square error (RMSE), Chi-square $(\chi 2)$ and correlation coefficient (R2) were used to evaluate the performance of Weibull and Rayleigh functions.

\section{Wind speed data}

In this study, hourly time series wind speed data in Diyarbakır that were measured between the years 2014 and 2018 were statistically analyzed. Wind speed data were continuously recorded at a height of $30 \mathrm{~m}$ using a cup-generator anemometer located at the Diyarbakır station of the Turkish State Meteorological Service. The continuously recorded wind speed data were averaged over 1 hour and stored as hourly values.

\section{Performance analysis}

The model selection criteria required in determining the optimal statistical distribution for the observed wind speed are introduced in this section.

\subsection{Statistical criteria}

In the literature, there are studies on the wind speed statistics [11-24]. Rayleigh distributions, where the two parameter Weibull and Weibull shape parameters are 2, are the most widely used distributions. Rayleigh distribution is less flexible than Weibull since it is single parameter, but the calculation of parameters is easier. It is known that the wind speed distribution approaches the Rayleigh distribution in the case where annual average wind speed is greater than 4.5 [10].

The general expression of the two parameter Weibull probability density function is presented in Eq. 1 .

$$
f_{w}(v)=\left(\frac{k}{c}\right)\left(\frac{v}{c}\right)^{k-1} \exp \left[-\left(\frac{v}{c}\right)^{k}\right]
$$

Here, $\mathrm{k}$ and $\mathrm{c}$ are the shape and scale parameters, respectively. The scale parameter $\mathrm{c}$ also has a reference value in the wind data. Weibull cumulative distribution function is determined by Eq. 2 . 


$$
F_{w}(v)=1-\exp \left[-\left(\frac{v}{c}\right)^{k}\right]
$$

The shape parameter is around 1 near the equator, 2 at temperate latitudes and around 3 for continuous wind areas [25].

The probability density function of the Rayleigh distribution and the cumulative distribution function are presented by Eq. 3 and Eq. 4 .

$$
\begin{gathered}
f_{w}(v)=\frac{2 v}{c^{2}} \exp \left[-\left(\frac{v}{c}\right)^{2}\right] \\
F_{R}(v)=1-\exp \left[-\left(\frac{v}{c}\right)^{2}\right]
\end{gathered}
$$

The biggest advantage of Rayleigh distribution is the determination of the distribution only with the average wind speed. The validity of Rayleigh distribution in wind studies was shown in many references [26]. In this study, the least squares method was used to find the parameters of the Weibull and Rayleigh distributions $[10,26]$. The average wind speed and the standard deviation of the wind speed are calculated using Eq. 5 and Eq. 6, respectively.

$$
\begin{gathered}
v_{m}=c \Gamma\left(1+\frac{1}{k}\right) \\
\sigma=\sqrt{c^{2}\left[\Gamma\left(1+\frac{2}{k}\right)-\Gamma^{2}\left(1+\frac{1}{k}\right)\right]}
\end{gathered}
$$

where $\lceil($ ) is the gamma function.

Based on the Weibull distribution, the wind speed with the largest frequency is calculated from Eq. $7[8]$.

$$
V_{\mathrm{mod}}=c\left(1-\frac{1}{k}\right)^{1 / k}
$$

Maximum wind speed is found by Eq. 8 [6].

$$
V_{\max }=c\left(\frac{k+2}{k}\right)^{1 / k}
$$

When it is $\mathrm{k}=2$ in the above-mentioned formulas, calculations are made for the Rayleigh distribution. The average wind power density is most generally calculated from Eq. 9:

$$
P_{m}=\int_{0}^{\infty} P(v) f(v) d v
$$


The average power density for the Weibull distribution is obtained from Eq. 10 as follows [10].

$$
P_{W}=\frac{1}{2} \rho c^{3}\left(1+\frac{3}{k}\right)
$$

The average power density for Rayleigh distribution is determined by Eq. 11:

$$
P_{R}=\frac{3}{\pi} \rho\left(v_{m}\right)^{3}
$$

In this study, the coefficient of determination $\left(R^{2}\right)$ based on the theoretical and observed probabilities of distributions, root mean square error (RMSE) and chi-square $\left(\chi^{2}\right)$ criteria were selected as Eq. 12, Eq. 13 and Eq. 14 in the statistical modeling of wind speed data of distributions:

$$
\begin{gathered}
R^{2}=\frac{\sum_{i=1}^{N}\left(y_{i}-z_{i}\right)^{2}-\sum_{i=1}^{N}\left(x_{i}-y_{i}\right)^{2}}{\sum_{i=1}^{N}\left(y_{i}-z_{i}\right)^{2}} \\
x^{2}=\frac{\sum_{i=1}^{N}\left(y_{i}-x_{i}\right)^{2}}{N-n} \\
R M S E=\left[\frac{1}{N} \sum_{i=1}^{N}\left(y_{i}-x_{i}\right)^{2}\right]^{1 / 2}
\end{gathered}
$$

where $y_{\mathrm{i}}$ is the measured data, $z_{\mathrm{i}}$ is the mean value, $x_{i}$ is the predicted data with the Weibull or Rayleigh distribution, $N$ is the number of observations and $n$ is the number of constants. Thus, the more distribution function can be selected by the highest value of $R^{2}$ and the lowest values of RMSE and $\chi^{2}$. $R^{2}$ ranges between 0 and 1 as a measure of the predictive power of a model and its approaches to 1 indicates that predictive power of the model has increased [26].

\section{Results and discussion}

The monthly mean wind speeds are presented in Figure 1. As it can be seen in Figure 1, the mean wind speed varies between $1.78 \mathrm{~m} / \mathrm{s}$ and $3.14 \mathrm{~m} / \mathrm{s}$, with a yearly mean of $2.64 \mathrm{~m} / \mathrm{s}$. Maximum value of the mean wind speed is $4.5 \mathrm{~m} / \mathrm{s}$ in July of 2016 , whereas minimum value is $1.30 \mathrm{~m} / \mathrm{s}$ in November of 2014. 


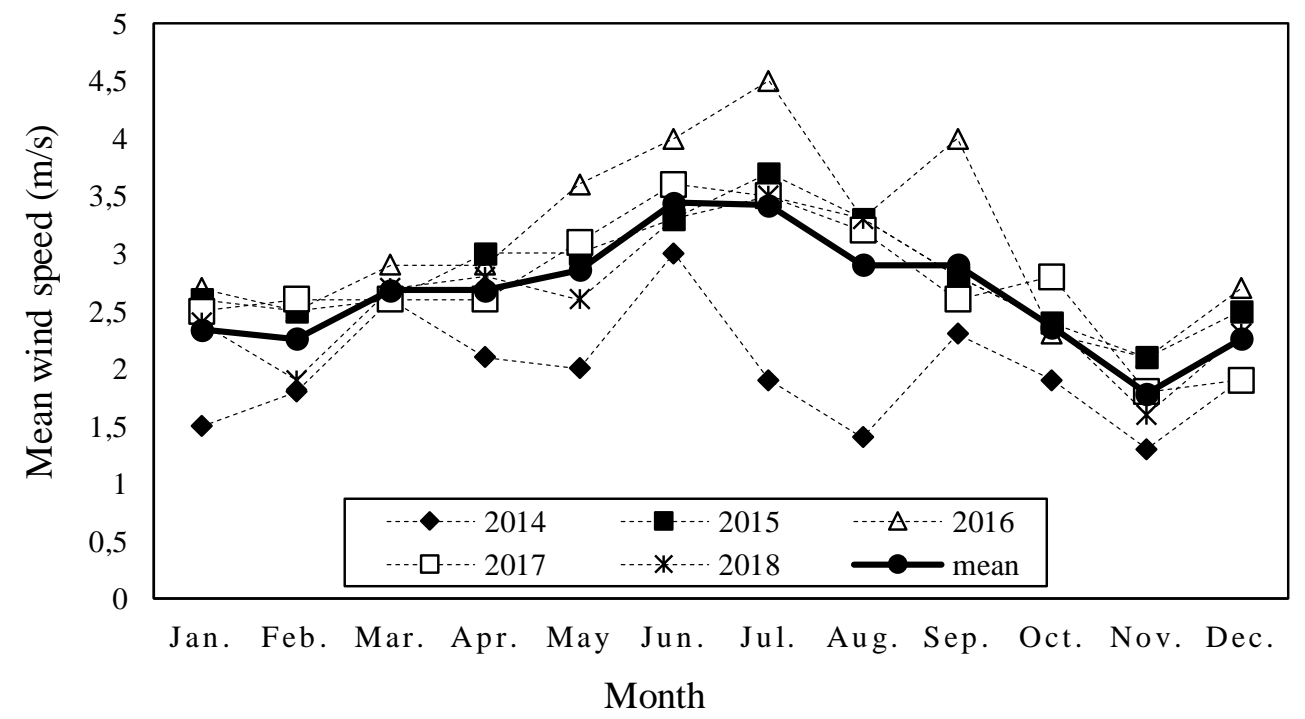

Figure 1. Monthly mean wind speed in Diyarbakır

The diurnal variation of the mean wind speed values is plotted in Figure 2. According to the yearly average results, the wind speed is the lowest as $0.98 \mathrm{~m} / \mathrm{s}$ the hours of 03:00 in 2014, and is the highest as $4.33 \mathrm{~m} / \mathrm{s}$ the hours of 13:00 in 2016 .

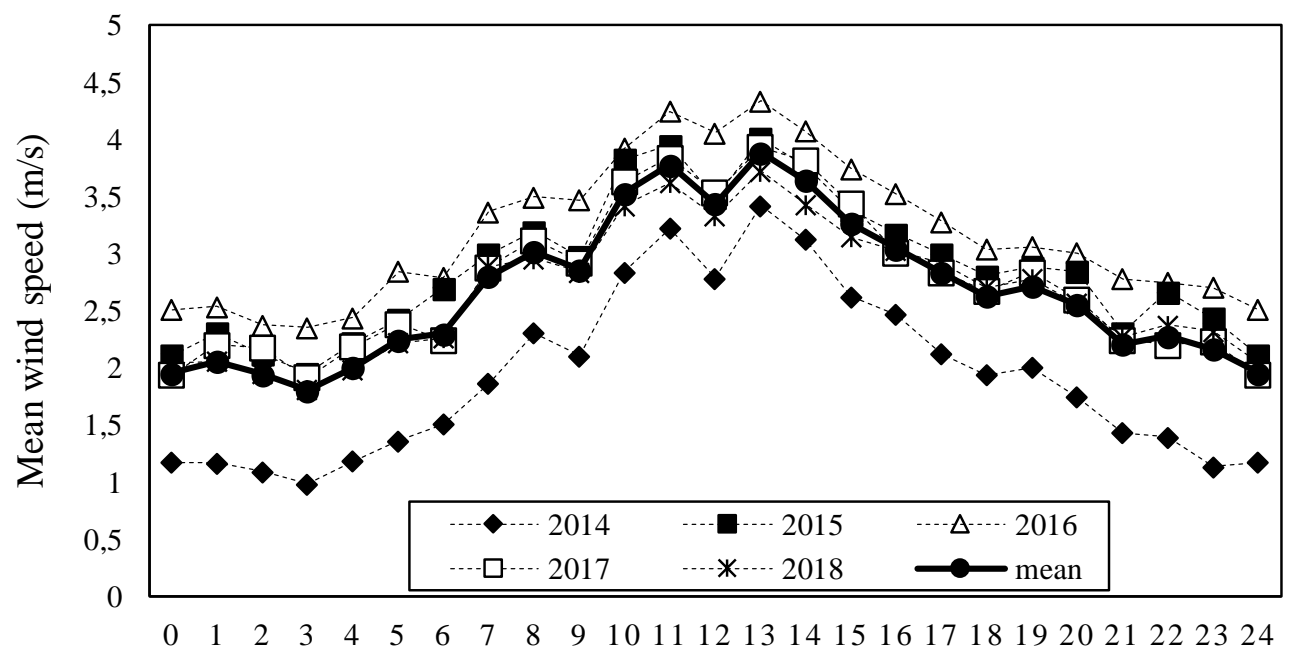

Hour of day

Figure 2. Diurnal variation of mean wind speed for the period of 2014-2018 in Diyarbakır

In Table 1, available time-series data were arranged as frequency distribution format for the period between 2014 and 2018. In the second column of Table 1, wind speed is grouped into classes. In the third column, mean wind speeds are calculated for each speed class intervals. The fourth column shows the frequency of the occurrence of each speed class. The probability density distribution is presented in the fifth column. In the last columns, the theoretical frequency values calculated from the Weibull and Rayleigh distributions are presented, respectively. 
Table 1. Comparison of the actual probability distribution of wind speeds derived from measured data with Weibull and Rayleigh approximations for whole years

\begin{tabular}{cccccc}
\hline $\mathbf{j}$ & $\boldsymbol{v}_{\boldsymbol{j}}$ & $\boldsymbol{v}_{\boldsymbol{m}, \boldsymbol{j}}$ & Actual data & Weibull distribution & Rayleigh distribution \\
\hline 1 & $0-1$ & 0.5 & 0.1398264 & 0.1511543 & 0.1808638 \\
2 & $1-2$ & 1.5 & 0.2055449 & 0.2271100 & 0.2467099 \\
3 & $2-3$ & 2.5 & 0.2752245 & 0.2466999 & 0.2156508 \\
4 & $3-4$ & 3.5 & 0.1630558 & 0.1856827 & 0.1543006 \\
5 & $4-5$ & 4.5 & 0.0865043 & 0.0967622 & 0.0959776 \\
6 & $5-6$ & 5.5 & 0.0524023 & 0.0360599 & 0.0515152 \\
7 & $6-7$ & 6.5 & 0.0372452 & 0.0103187 & 0.0236582 \\
8 & $7-8$ & 7.5 & 0.0203999 & 0.0024959 & 0.0093202 \\
9 & $8-9$ & 8.5 & 0.0106799 & 0.0005762 & 0.0031719 \\
10 & $9-10$ & 9.5 & 0.0048804 & 0.0001505 & 0.0009396 \\
11 & $10-11$ & 10.5 & 0.0023715 & $4.95245 \mathrm{E}-05$ & 0.0002440 \\
12 & $11-12$ & 11.5 & 0.0009869 & $1.90944 \mathrm{E}-05$ & $5.58849 \mathrm{E}-05$ \\
13 & $12-13$ & 12.5 & 0.0005129 & $7.72884 \mathrm{E}-06$ & $1.13513 \mathrm{E}-05$ \\
14 & $13-14$ & 13.5 & 0.0003252 & $3.1318 \mathrm{E}-06$ & $1.93884 \mathrm{E}-06$ \\
15 & $14-15$ & 14.5 & 0.0001313 & $1.25641 \mathrm{E}-06$ & $3.17865 \mathrm{E}-07$ \\
\hline
\end{tabular}

The yearly probability density and the cumulative distributions derived from the time-series data of Diyarbakır are presented in Figures 3 and 4, respectively. The yearly probability density and the cumulative distributions are presented in Figure 5 for all years.

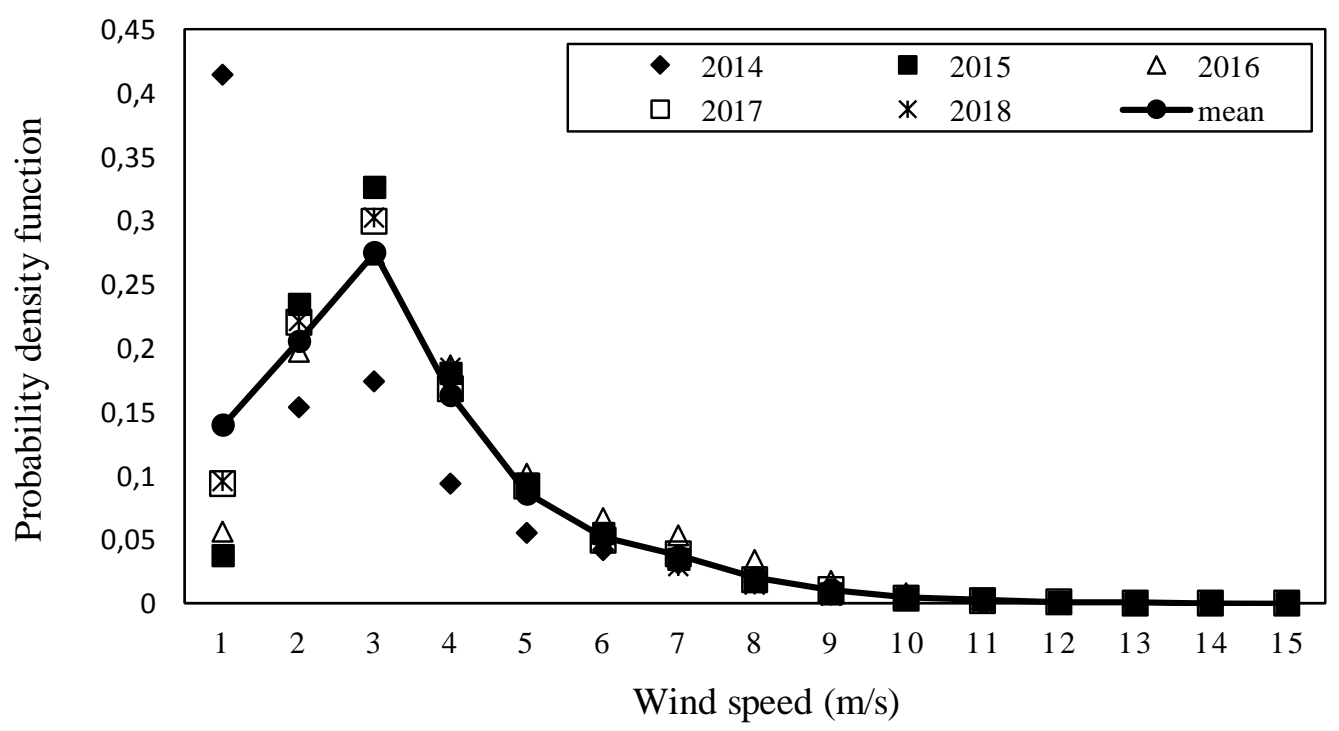

Figure 3. Yearly wind speed probability density distributions, derived from the measured hourly time series 


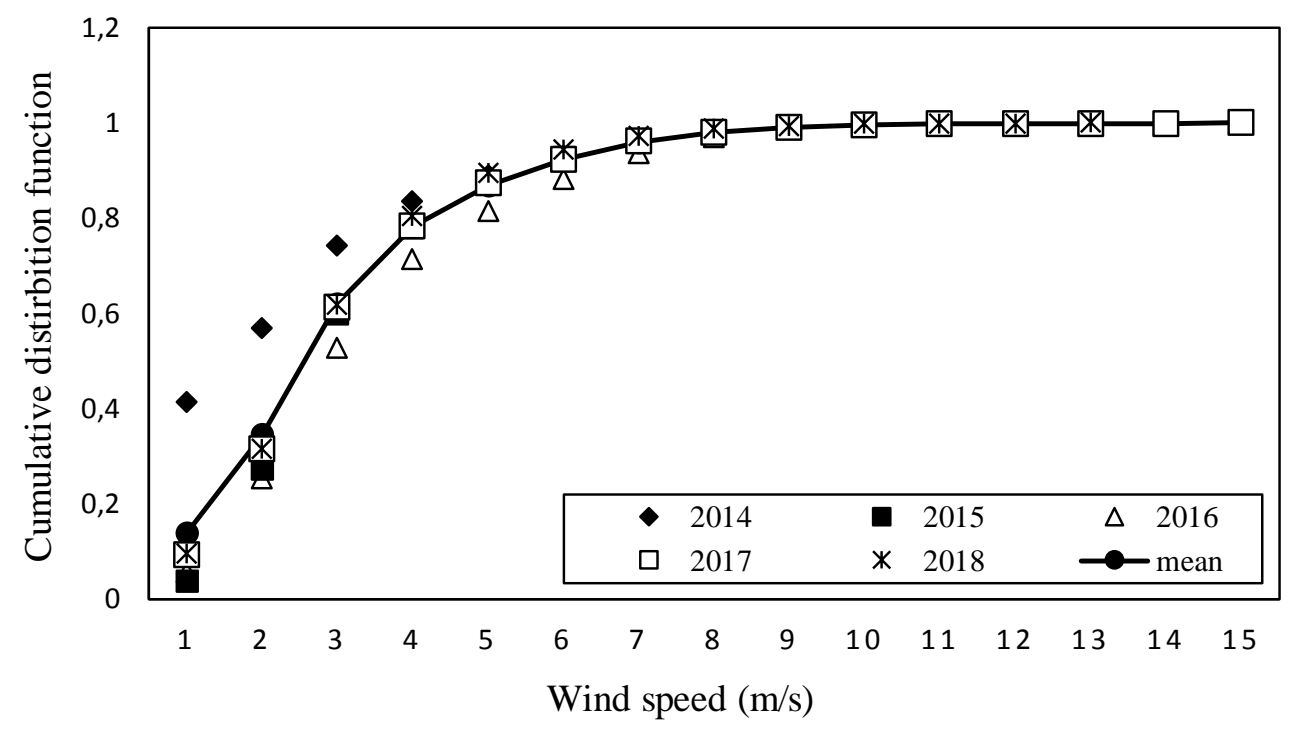

Figure 4. Yearly wind speed cumulative probability distributions, derived from the measured hourly time-series.

The monthly mean wind speed values $\left(v_{m}\right)$ and standard deviations $(\sigma)$ are presented in Table 2 to Weibull distribution for Diyarbakır, the period of 2014-2018. Most of the monthly mean wind speed values are between $1.0 \mathrm{~m} / \mathrm{s}$ and $4.0 \mathrm{~m} / \mathrm{s}$, but only a few of them are over $4.0 \mathrm{~m} / \mathrm{s}$ and under $2.0 \mathrm{~m} / \mathrm{s}$. In general, it is determined that the highest mean wind speed values are in June and July, and the lowest mean wind speed values are in November and December. After analyzing 48 months of the wind speed data, it is possible to conclude that the wind speed distribution significantly differs from one month to the next. The monthly and yearly standard deviation values are mostly between $1.0 \mathrm{~m} / \mathrm{s}$ and $3.0 \mathrm{~m} / \mathrm{s}$, with only a few under $4.0 \mathrm{~m} / \mathrm{s}$.

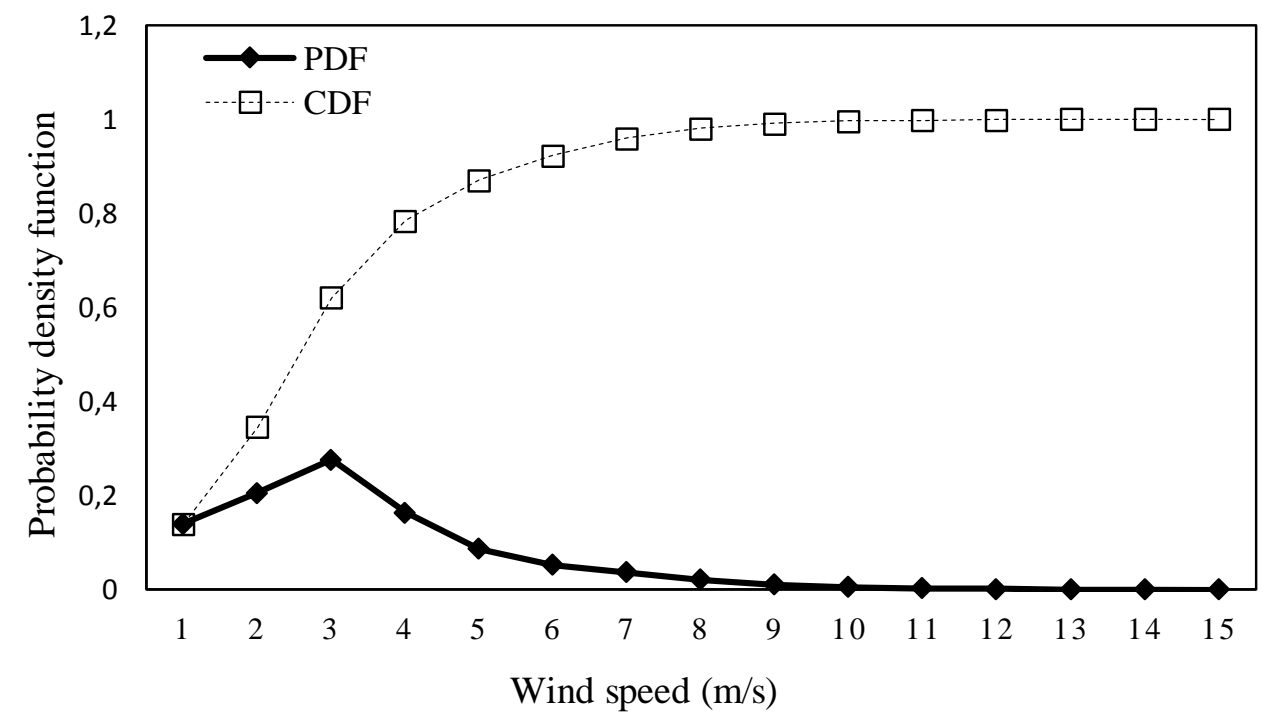

Figure 5. Yearly wind speed probability density and cumulative probability distributions derived from the measured data for whole years 
Table 2. Monthly mean wind speed and standard deviations to Weibull distribution

\begin{tabular}{lrrrrrrrrrrr}
\hline Years & \multicolumn{2}{c}{$\mathbf{2 0 1 4}$} & \multicolumn{2}{c}{$\mathbf{2 0 1 5}$} & \multicolumn{2}{c}{$\mathbf{2 0 1 6}$} & \multicolumn{2}{c}{$\mathbf{2 0 1 7}$} & \multicolumn{2}{c}{$\mathbf{2 0 1 8}$} \\
\hline Parameters & $v_{m}$ & $\sigma$ & $v_{m}$ & $\sigma$ & $v_{m}$ & $\sigma$ & $v_{m}$ & $\sigma$ & $v_{m}$ & $\sigma$ \\
\hline January & 1.180 & 0.323 & 2.820 & 1.517 & 2.832 & 1.182 & 2.967 & 1.583 & 2.977 & 1.584 \\
February & 2.531 & 1.598 & 3.011 & 2.613 & 3.058 & 2.692 & 2.824 & 1.125 & 2.497 & 1.033 \\
March & 2.812 & 0.871 & 3.005 & 2.746 & 3.358 & 2.768 & 3.074 & 2.597 & 3.037 & 2.393 \\
April & 2.466 & 1.899 & 3.278 & 2.784 & 3.362 & 2.066 & 3.114 & 2.521 & 3.271 & 2.716 \\
May & 2.365 & 1.088 & 2.298 & 1.170 & 2.297 & 1.395 & 2.258 & 1.145 & 3.124 & 2.737 \\
June & 1.803 & 1.206 & 2.317 & 1.437 & 2.976 & 1.066 & 2.282 & 1.843 & 2.295 & 1.741 \\
July & 2.409 & 0.869 & 2.992 & 1.056 & 2.980 & 1.316 & 2.309 & 1.927 & 2.290 & 1.985 \\
August & 1.056 & 0.969 & 2.313 & 1.455 & 2.311 & 1.567 & 2.287 & 1.317 & 2.282 & 1.006 \\
September & 1.599 & 0.664 & 3.392 & 2.049 & 2.305 & 1.991 & 3.115 & 2.770 & 3.398 & 2.317 \\
October & 2.601 & 1.401 & 2.974 & 1.549 & 2.867 & 1.488 & 3.214 & 1.640 & 3.016 & 2.423 \\
November & 1.593 & 0.564 & 2.833 & 1.326 & 2.570 & 1.867 & 2.440 & 1.920 & 2.396 & 1.856 \\
December & 2.535 & 1.298 & 2.814 & 1.230 & 3.127 & 2.595 & 2.420 & 1.890 & 2.711 & 1.071 \\
\hline
\end{tabular}

The yearly values of the two Weibull parameters, the scale parameter $\mathrm{c}(\mathrm{m} / \mathrm{s})$ and shape parameter $\mathrm{k}$ (dimensionless), calculated from the long term wind data for Diyarbakır are presented in Table 3. Furthermore, monthly values of $\mathrm{k}$ and $\mathrm{c}$ are also presented in Table 3. It is obvious that the parameter $\mathrm{k}$ has a much smaller, temporal variation than the parameter $\mathrm{c}$. The range of $\mathrm{k}$ is between 0.861 and 3.42, while the c value varies between 0.923 to $5.70 \mathrm{~m} / \mathrm{s}$. The lowest value of the scale parameter is $0.923 \mathrm{~m} / \mathrm{s}$ and is found in July of 2014, while the highest value is 5.70, which occurred in July of 2016. The highest k value is in December of 2014 and the lowest is found in June of 2014. The mean k and c vales is 2.47 and $3.27 \mathrm{~m} / \mathrm{s}$, respectively. The mean wind intensity and standard deviation values are important in predicting the shape and scale parameters.

Table 3. Monthly shape parameter (k) and scale parameter (c) values distribution for period of 2014-2018

\begin{tabular}{lcccccccccc}
\hline Years & \multicolumn{2}{c}{$\mathbf{2 0 1 4}$} & \multicolumn{2}{c}{$\mathbf{2 0 1 5}$} & \multicolumn{2}{c}{$\mathbf{2 0 1 6}$} & \multicolumn{2}{c}{$\mathbf{2 0 1 7}$} & \multicolumn{2}{c}{$\mathbf{2 0 1 8}$} \\
\hline Parameters & $k$ & $c$ & $k$ & $c$ & $k$ & $c$ & $k$ & $c$ & $k$ & $c$ \\
\hline January & 2.1509 & 1.3649 & 3.0342 & 3.0143 & 2.1729 & 3.1172 & 2.7634 & 3.1698 & 2.7378 & 3.2835 \\
February & 1.5694 & 2.7567 & 3.0341 & 3.1927 & 2.9882 & 3.2845 & 2.0884 & 3.1645 & 2.7785 & 2.7825 \\
March & 1.3298 & 3.0348 & 3.3374 & 3.1696 & 2.3797 & 3.6661 & 2.6394 & 3.3692 & 2.2728 & 3.3516 \\
April & 1.0493 & 1.9211 & 2.9098 & 3.4049 & 3.0479 & 3.5854 & 2.2860 & 3.4716 & 2.5746 & 3.5141 \\
May & 1.1825 & 1.1309 & 2.9503 & 3.7306 & 2.3783 & 4.2768 & 2.3694 & 4.0386 & 2.8424 & 3.3962 \\
June & 0.8618 & 2.1454 & 2.5112 & 4.2356 & 2.6510 & 4.7366 & 2.6246 & 4.5460 & 3.0244 & 4.1953 \\
July & 1.5072 & 0.9238 & 2.7949 & 4.6279 & 2.8789 & 5.7097 & 2.9261 & 4.4236 & 2.5325 & 4.7439 \\
August & 1.6694 & 1.0230 & 2.8323 & 4.0554 & 3.0107 & 4.0496 & 2.6403 & 4.0432 & 3.1674 & 4.3388 \\
September & 0.9979 & 1.6627 & 2.9533 & 3.6205 & 2.2008 & 4.9795 & 2.9385 & 3.3787 & 3.2850 & 3.6799 \\
October & 1.2652 & 2.5233 & 2.9344 & 3.1827 & 3.0083 & 3.0936 & 2.5876 & 3.4361 & 2.3261 & 3.3562 \\
November & 1.3567 & 1.6558 & 2.7325 & 3.0730 & 2.2164 & 2.8545 & 2.7242 & 2.7005 & 2.6145 & 2.6851 \\
December & 3.4263 & 2.7561 & 2.6878 & 3.0041 & 2.6328 & 3.3703 & 2.7104 & 2.6788 & 2.3312 & 3.0085 \\
\hline
\end{tabular}


In Figure 6, the variation of the Weibull probability distribution with wind speed is plotted by years. The highest probability value according to the Weibull probability distribution function was obtained as 0.35 in 2014.

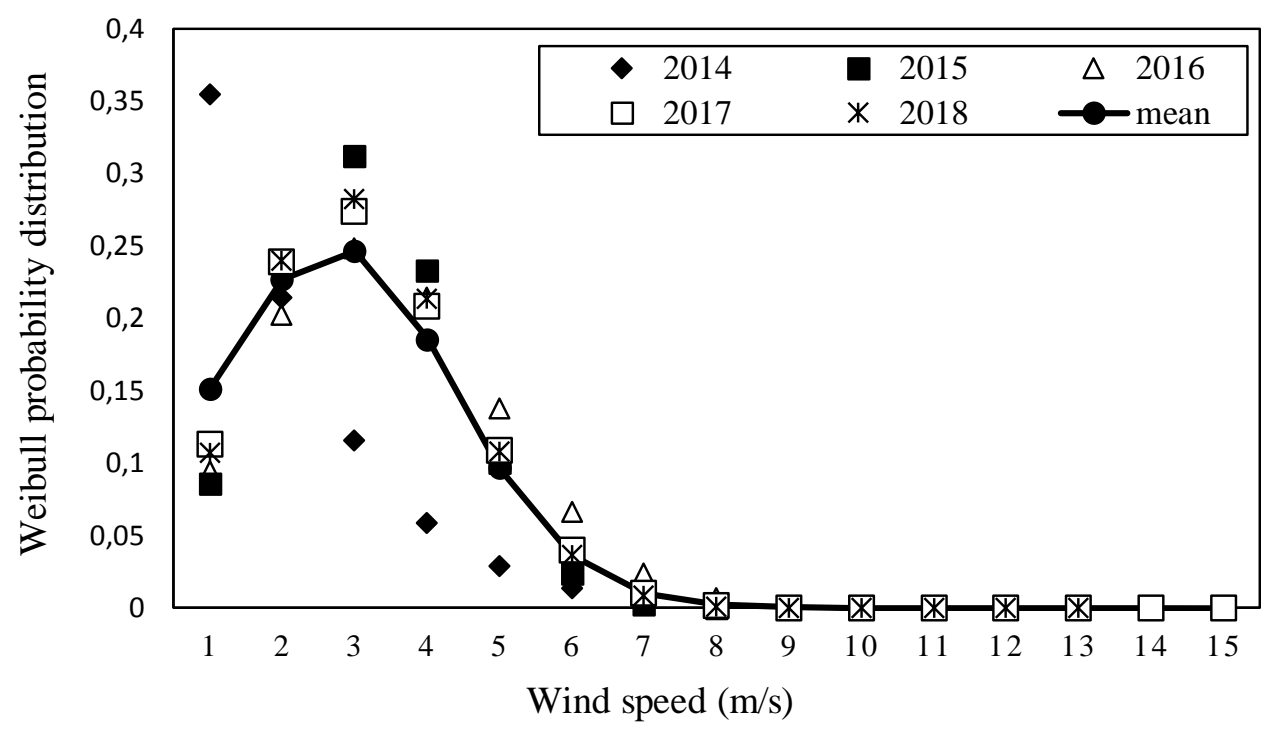

Figure 6. Yearly Weibull probability density distributions for the period of 2014-2018 in Diyarbakır

The Weibull and Rayleigh approximations of the actual probability distribution of wind speeds are presented in Figure 7, while a comparison of the two approximations is presented in Table 4. In Figure 7, the probability distribution of the actual data, the Weibull probability distribution, and the Rayleigh probability distribution are plotted versus the wind speed according to the average of five years data. The probability ratio of the Rayleigh distribution is higher than the Weibull distribution.

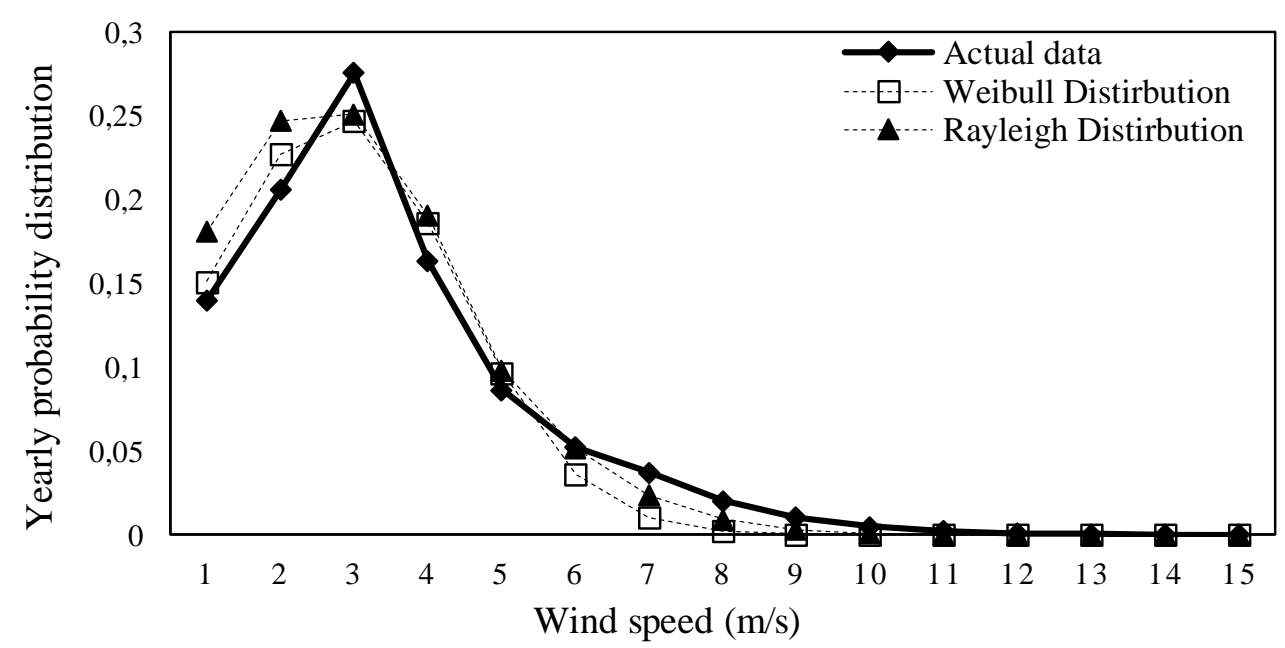

Figure 7. Weibull and Rayleigh approximations of the actual probability distribution of wind speeds

The values of the statistical parameters $\left(R^{2}, R M S E\right.$, and $\left.\chi^{2}\right)$ obtained from Weibull and Rayleigh distributions are given in Table 4. The $R^{2}$ value is found between 0.92-0.98 in the Weibull distribution and $0.90-0.93$ in the Rayleigh distribution. The RMSE values range from $1.09 \times 10^{-5}$ to $4.72 \times 10^{-5}$ in the 
Weibull distribution and from $2.69 \times 10^{-5}$ to $1.84 \times 10^{-4}$ in the Rayleigh distribution. The $\chi^{2}$ values vary between $2.59 \times 10^{-5}$ and $1.08 \times 10^{-4}$ in the Weibull distribution and between $6.61 \times 10^{-5}$ and $3.95 \times 10^{-4}$ in the Rayleigh distribution. As can be seen in Table 4, the highest $R^{2}$ value is obtained by using the Weibull distribution. However, the results have shown that the RMSE and $\chi^{2}$ values of the Weibull distribution are lower than the values obtained for the Rayleigh distribution. As a result, the Weibull approximation is found to be the most accurate distribution according to the highest value of $R^{2}$ and the lowest values of $R M S E$ and $\chi^{2}$.

Table 4. The statistical analysis parameters for yearly wind speed distributions in Diyarbakır

\begin{tabular}{ccccccc}
\hline \multirow{2}{*}{ Years } & \multicolumn{3}{c}{ Weibull Distribution } & \multicolumn{3}{c}{ Rayleigh Distribution } \\
\cline { 2 - 6 } & \multicolumn{1}{c}{$R^{2}$} & RMSE & $\chi^{2}$ & $R^{2}$ & RMSE & $\chi^{2}$ \\
\cline { 2 - 7 } $\mathbf{2 0 1 4}$ & 0.919 & 0.00047219 & 0.0010897 & 0.900 & 0.00184337 & 0.0039501 \\
$\mathbf{2 0 1 5}$ & 0.947 & 0.00025287 & 0.0005835 & 0.911 & 0.00068175 & 0.0014609 \\
$\mathbf{2 0 1 6}$ & 0.941 & 0.00020512 & 0.0004733 & 0.915 & 0.00029723 & 0.0006369 \\
$\mathbf{2 0 1 7}$ & 0.963 & 0.00015103 & 0.0003485 & 0.934 & 0.00026925 & 0.0005770 \\
$\mathbf{2 0 1 8}$ & 0.976 & 0.00010960 & 0.0002591 & 0.933 & 0.00030541 & 0.0006617 \\
\hline
\end{tabular}

Fig. 8 shows the monthly change in the $R^{2}$ obtained from the Weibull and Rayleigh distributions for Diyarbakır using the ten-year data. The range of $R^{2}$ values change from 0.89 to 0.93 in the Weibull distribution and 0.89 to 0.97 in the Rayleigh distribution. Because the $R^{2}$ value is closer to 1 in the Weibull distribution, it is understood that the Weibull distribution is more suitable for modeling the wind data for Diyarbakır.

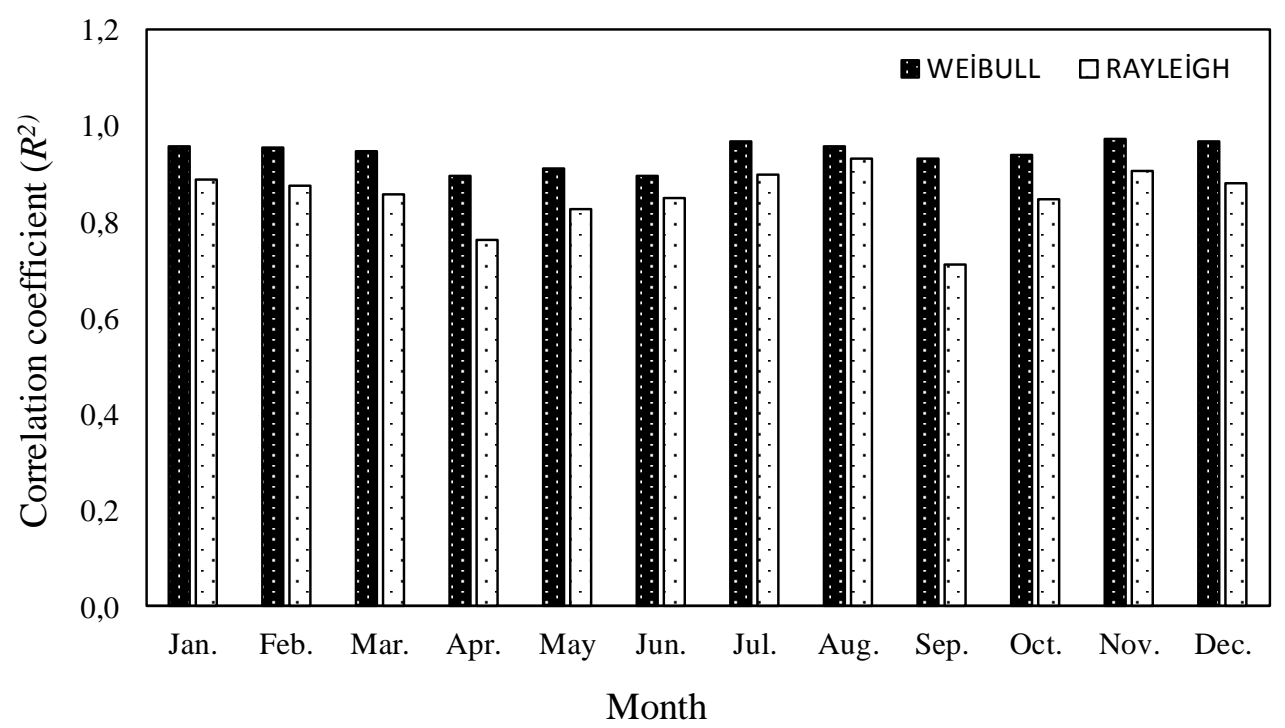

Figure 8. The change of correlation coefficient values obtained from Weibull and Rayleigh distribution to months

The Weibull distribution parameters and the Rayleigh distribution parameters are given in Table 5 and Table 6 according to years, respectively. The maximum mean velocity $\left(V_{\max }\right)$ in the Weibull distribution ranged from 4.23 to $5.02 \mathrm{~m} / \mathrm{s}$ and the mean power density $\left(P_{\mathrm{w}}\right)$ ranged from 17.87 to $41.99 \mathrm{~W} / \mathrm{m}^{2}$. In the Rayleigh distribution, $V_{\max }$ varied from 2.95 to $5.22 \mathrm{~m} / \mathrm{s}$ and $P_{R}$ varied from 11.95 to $26.20 \mathrm{~W} / \mathrm{m}^{2}$. 
Table 5. Weibull distribution parameters

\begin{tabular}{cccccccc}
\hline Years & $\mathbf{k}$ & $\mathbf{c}(\mathbf{m} / \mathbf{s})$ & $\mathbf{V}_{\mathbf{m}}(\mathbf{m} / \mathbf{s})$ & $\boldsymbol{\sigma}(\mathbf{m} / \mathbf{s})$ & $\mathbf{V}_{\mathbf{m o d}}(\mathbf{m} / \mathbf{s})$ & $\mathbf{V}_{\max }(\mathbf{m} / \mathbf{s})$ & $\mathbf{P}_{\mathbf{w}}\left(\mathbf{W} / \mathbf{m}^{2}\right)$ \\
\hline $\mathbf{2 0 1 4}$ & 1.5305 & 1.9082 & 1.79101 & 1.89879 & 0.3530 & 4.2385 & 17.867 \\
$\mathbf{2 0 1 5}$ & 2.8927 & 3.5259 & 3.14357 & 3.90231 & 2.9562 & 4.2554 & 27.465 \\
$\mathbf{2 0 1 6}$ & 2.6305 & 3.8937 & 3.46241 & 4.16010 & 3.0463 & 5.0254 & 41.991 \\
$\mathbf{2 0 1 7}$ & 2.6082 & 3.5350 & 3.14177 & 3.76184 & 2.8014 & 4.5430 & 29.579 \\
$\mathbf{2 0 1 8}$ & 2.7073 & 3.5280 & 3.14007 & 3.81948 & 2.8385 & 4.4730 & 28.852 \\
\hline
\end{tabular}

Table 6. Rayleigh distribution parameters

\begin{tabular}{ccccccc}
\hline Years & $\mathbf{c}(\mathbf{m} / \mathbf{s})$ & $\mathbf{V}_{\mathbf{m}}(\mathbf{m} / \mathbf{s})$ & $\boldsymbol{\sigma}(\mathbf{m} / \mathbf{s})$ & $\mathbf{V}_{\mathbf{m o d}}(\mathbf{m} / \mathbf{s})$ & $\mathbf{V}_{\mathbf{m a x}}(\mathbf{m} / \mathbf{s})$ & $\mathbf{P}_{\mathbf{R}}\left(\mathbf{W} / \mathbf{m}^{\mathbf{2}}\right)$ \\
\hline $\mathbf{2 0 1 4}$ & 2.3461 & 2.07913 & 2.33091 & 1.4762 & 2.9524 & 11.957 \\
$\mathbf{2 0 1 5}$ & 3.2013 & 2.83712 & 3.48380 & 2.6102 & 5.2204 & 26.049 \\
$\mathbf{2 0 1 6}$ & 3.2011 & 2.83686 & 3.37859 & 2.8209 & 5.6418 & 26.201 \\
$\mathbf{2 0 1 7}$ & 3.0376 & 2.69196 & 3.18978 & 2.5545 & 5.1089 & 22.546 \\
$\mathbf{2 0 1 8}$ & 3.1306 & 2.77441 & 3.32709 & 2.5427 & 5.0854 & 24.739 \\
\hline
\end{tabular}

The variation of mean wind speed with Weibull power density and Rayleigh power density are showed in Fig. 9 and in Fig. 10 with respect to years, respectively. The mean wind velocity is determined as $2.93 \mathrm{~m} / \mathrm{s}$ for Weibull distribution and $2.64 \mathrm{~m} / \mathrm{s}$ for Rayleigh distribution. In the Weibull distribution, the highest power density is $41.99 \mathrm{~W} / \mathrm{m}^{2}$ in 2016 and the lowest power density is $17.87 \mathrm{~W} / \mathrm{m}^{2}$ in 2014 and the mean power density is $29.15 \mathrm{~W} / \mathrm{m}^{2}$. In the Rayleigh distribution, the highest and the lowest power density is determined as $26.20 \mathrm{~W} / \mathrm{m}^{2}$ in 2016 and $11.95 \mathrm{~W} / \mathrm{m} 2$ in 2014 , respectively, and but also the mean power density is obtained as $22.29 \mathrm{~W} / \mathrm{m}^{2}$.

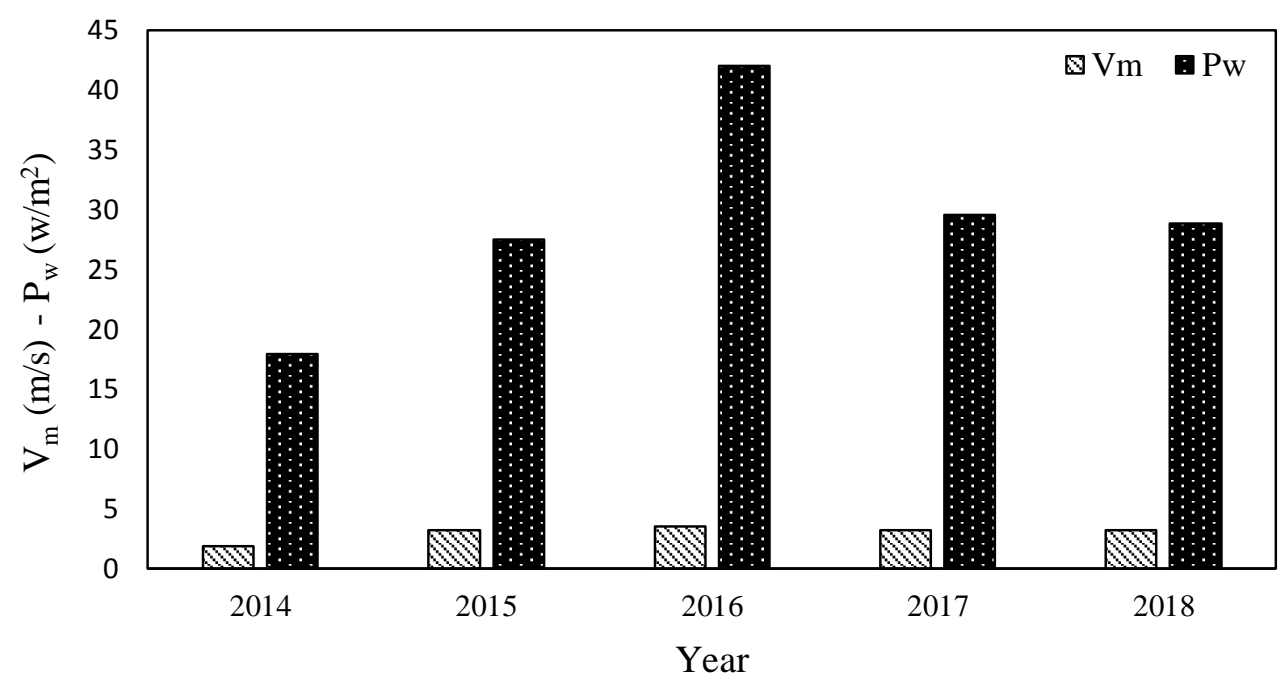

Figure 9. Yearly mean power density and wind speed according to Weibull distribution 


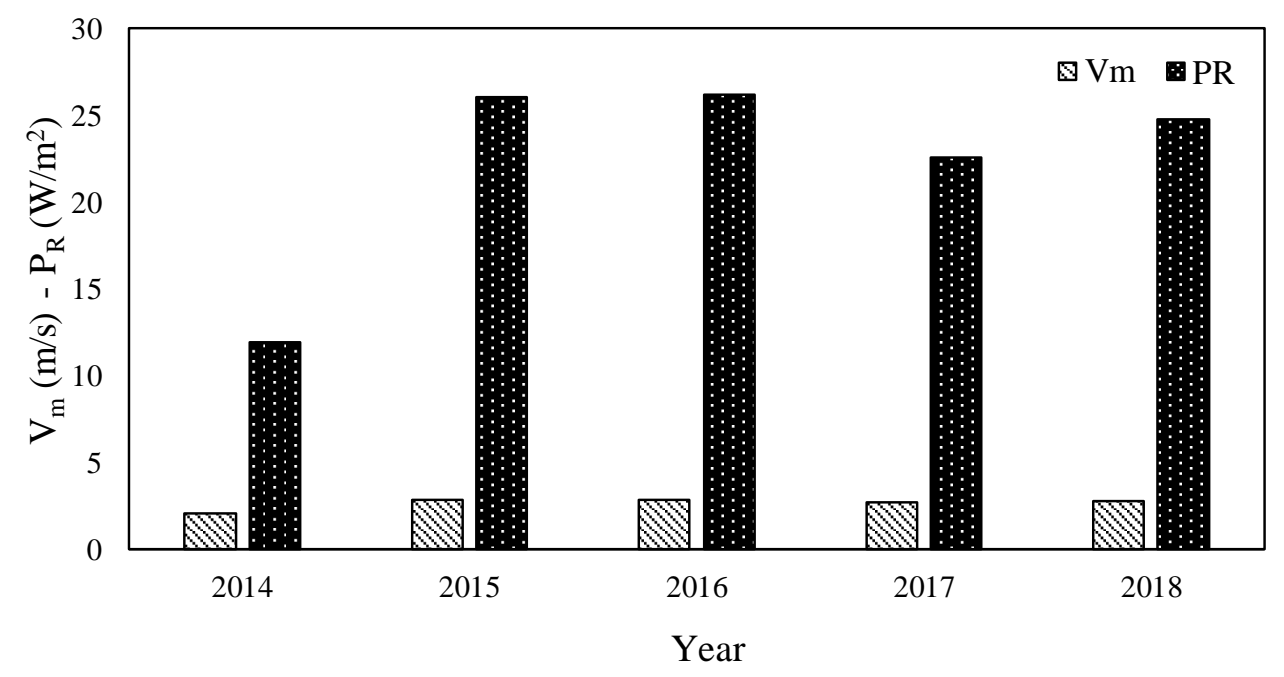

Figure 10. Yearly mean power density and wind speed according to Rayleigh distribution

\section{Conclusion}

The wind characteristics of Diyarbakir were statistically analyzed. Wind speed data were obtained for five years (2014-2018). Probability density distributions and power density distributions were obtained from time series data and distribution parameters were calculated. Two probability density functions were added to the wind speeds measured on a monthly and yearly basis. Based on the Weibull and Rayleigh models, the wind energy potential of Diyarbakır was investigated. The results can be summarized as the following:

1) Within five years, the Weibull distribution provides a better estimate of wind power potential density than the Rayleigh distribution. This is seen from the results of the correlation coefficient.

2) The Weibull model is generally better in fitting the measured yearly probability density distributions than the Rayleigh model, to the statistical criteria such as $R^{2}$, RMSE and $\chi^{2}$. Therefore, it was concluded that it would be better to use the Weibull distribution in the analysis of wind data of Diyarbakır.

3) The values of the shape parameter (k) and scale parameter (c) at Diyarbakır were examined. The yearly mean values of $k$ and $c$ for Weibull distribution were determined as 2.47 and $3.27 \mathrm{~m} / \mathrm{s}$ over a five year period of 2014-2018. The yearly mean c value for Rayleigh distribution was found $3.39 \mathrm{~m} / \mathrm{s}$.

4) It is indicated by the mean value of wind speed and energy intensity measured at the location that economical electricity production is not provided from wind power by the current technology and that the measurements need to be assessed in the long term in line with the technological developments and reduction in the cost of turbines. In conclusion, average monthly power and annual average power densities in Diyarbakir are not appropriate directly to the network support with wind energy systems. 


\section{Nomenclature}

$\boldsymbol{A}$ : Blade sweep area $\left(\mathrm{m}^{2}\right)$

$\boldsymbol{c}:$ Weibull scale parameter $(\mathrm{m} / \mathrm{s})$

$f(v)$ : Probability density function

$f j$ : Frequency of occurrence of each speed class

$\boldsymbol{F}(v)$ : Cumulative distribution function

$\boldsymbol{k}:$ Weibull shape parameter

$\boldsymbol{n}$ : Number of wind speed classes

$N$ : Number of hours in the period of time considered, number of observations

$\boldsymbol{P}$ : Power density $\left(\mathrm{W} / \mathrm{m}^{2}\right)$

$\boldsymbol{R M S E}$ : Root mean square error

$\boldsymbol{R}^{2}:$ Correlation coefficient

$\boldsymbol{V}:$ Wind speed $(\mathrm{m} / \mathrm{s})$

$\boldsymbol{x}_{i}$ : ith measured value

$y_{i}$ : ith calculated value

$z_{i}$ : mean value of the experimental data

\section{Subscripts}

$\boldsymbol{m}:$ mean

$\max :$ maximum

$\bmod :$ largest frequency

$\boldsymbol{R}:$ : Rayleigh

$\boldsymbol{W}$ : Weibull

\section{References}

[1] Kaplan, Y. A. "Evaluation of Wind Energy in Osmaniye Region Using Rayleigh and Weibull Distributions", Süleyman Demirel University, Journal of Natural and Applied Sciences Volume 20, Issue 1, 2016, 62-71

[2] Karadenizli A, Eker M .K., "Determination of Weibull function parameters by using 6 different methods by using the data of Balıkesir-Balya meteorological station", Dokuz Eylül University Faculty of Engineering Science and Engineering Journal, Volume 17, Issue 3, 2015, s.163-175

[3] Hepbasli A, Ozgener O. "A review on the development of wind energy in Turkey". Renewable \& Sustainable Energy Reviews 2004; 8(3): 257-276.

[4] Iş̧k, E., İnallı, M., Celik, E. "Approaches to Calculate the Heating and Cooling Degree Day Values: The Case of Provinces in Turkey", Arabian Journal for Science and Engineering, 2019, 1-17

[5] Işık, E., İnallı, M. "Artificial Neural Networks and Adaptative Neuro-Fuzzy Inference Systems Approaches to Forecast the Meteorological Data for HVAC: The Case of Cities for Turkey", Energy, $2018,154,7-16$ 
[6] Kentli F., and Yilmaz M. "Obtaining the optimum efficiency electrical energy under Diyarbakir conditions using solar tracking system involving PV panel." Energy Education Science and Technology Part A 30 (2012): 613-620.

[7] Y1lmaz, M., and Kentli F. "Increasing of electrical energy with solar tracking system at the region which has Turkey's most solar energy potential." Journal of Clean Energy Technologies 3.4 (2015): 287-290.

[8] Yilmaz M. "Real Measure of a Transmission Line Data with Load Fore-cast Model for The Future." Balkan Journal of Electrical and Computer Engineering 6.2: 73-77.

[9] Akkılıç K., Ocak Y.S. and Yılmaz M. "Analysing enhancement of electricity generating capacity with solar tracking system of the most sunning region of Turkey." Journal of Clean Energy Technologies 3.4 (2015): 291-295.

[10] Akpınar E. K, Balpetek N., "Statistical analysis of wind energy potential of Elazı ğ province according to Weibull and Rayleigh distributions", Journal of the Faculty of Engineering and Architecture of Gazi University 34:1 (2019) 569-580

[11] Turksoy F. "Investigation of wind power potential at Bozcaada, Turkey". Renewable Energy, 6(8), 917-923, 1995.

[12] Tolun S, Mentes S, Aslan Z, Yukselen MA. "The wind energy potential of Gokceada in the northern Aegean sea”. Renewable Energy, 6(7), 679-685, 1995.

[13] Eskin N, Artar H, Tolun S. "Wind energy potential of Gokceada Island in Turkey". Renewable \& Sustainable Energy Reviews, 12(3), 839-851, 2008.

[14] Incecik S, Erdogmus F. "An investigation of the wind power potential on the western coast of Anatolia”. Renewable Energy, 6(7), 863-865, 1995.

[15] Sen Z, Sahin AD. "Regional assessment of wind power in western Turkey by the cumulative semivariogram method”. Renewable Energy, 12(2), 169-177, 1997.

[16] Durak M, Sen Z. "Wind power potential in Turkey and Akhisar case study". Renewable Energy, 25(3), 463-472, 2002.

[17] Karsli VM, Gecit C. "An investigation on wind power potential of Nurdagi-Gaziantep, Turkey". Renewable Energy, 28(5), 823-830, 2003.

[18] Bilgili M, Sahin B, Kahraman A. "Wind energy potential in Antakya and Iskenderun Regions, Turkey”. Renewable Energy, 29(10), 1733-1745, 2004. 
[19] Akpinar E.K. "A statistical investigation of wind energy potential". Energ Source Part A, 28(9), 807-820, 2006.

[20] Gokcek M, Bayulken A, Bekdemir S. "Investigation of wind characteristics and wind energy potential in Kirklareli, Turkey”. Renewable Energy, 32(10), 1739-1752, 2007.

[21] Ucar A, Balo F. "A seasonal analysis of wind turbine characteristics and wind power potential in Manisa, Turkey”. International Journal of Green Energy, 5(6), 466-479, 2008.

[22] Gungor A, Eskin N. "The characteristics that define wind as an energy source". Energy Source Part A, 30(9), 842-855, 2008.

[23] Sahin B, Bilgili, M. "Wind characteristics and energy potential in Belen-Hatay, Turkey". International Journal of Green Energy, 6(2), 157-172, 2009.

[24] Ucar A, Balo, F. "Investigation of wind characteristics and assessment of wind-generation potentiality in Uludağ-Bursa, Turkey”. Applied Energy, 86(3), 333-339, 2009.

[25] İmal M., Şekkeli M., Yıldız C. “Kahramanmaran Sütçü İmam University Wind energy potential research and evaluation in main campus", KSU Journal of Engineering Sciences, Volume 15, Issue. $2,2012$.

[26] Balpetek N., "Use of Weibull and Rayleigh distributions to investigate the potential of wind energy", Firat University, Master Thesis, Elazı̆̆, 2017. 